ARTICLE OPEN

Check for updates

\title{
Increasing activity of tropical cyclones in East Asia during the mature boreal autumn linked to long-term climate variability
}

\author{
Joseph Basconcillo ${ }^{1,2,3}$ and II-Ju Moon (iD) ${ }^{1,3 凶}$
}

In recent years, the East Asian (EA) region experienced escalated cost of damages associated with tropical cyclones (TC) during the mature boreal autumn (i.e., September-October). Questions arise whether such increased TC-associated cost of damages are indicative of increasing activity of TCs in EA, particularly during the mature boreal autumn. Here we show evidence of significantly increasing activity of TCs in EA from 1981 to 2019 that is mainly accompanied by an abrupt regime shift in TC passage frequency since 1998. Such trend and shift are robustly linked to the shift of the Pacific Decadal Oscillation (PDO) to its negative phase in the mid-1990s. Characterized by warm sea surface temperature anomalies in the subtropical North Pacific, a negative PDO phase is related to the weakening of the East Asian subtropical jetstream and the westward displacement of the WNP subtropical high, which initiates a favorable steering environment for increased TC passages into the EA region. Contrasting environmental patterns are associated in a positive PDO phase. Considering the prominence of EA in the global economy, our paper contributes additional insights on long-term tropical cyclone risk reduction and management in the region.

npj Climate and Atmospheric Science (2022)5:4 ; https://doi.org/10.1038/s41612-021-00222-6

\section{INTRODUCTION}

In a year, there are about 25 tropical cyclones (TCs) that develop in the Western North Pacific (WNP) where 12 of the said number normally pass through East Asia (EA) (Fig. 1a, b) (see "Methods" on the definition of regional domains). The entire TC season in EA runs from June to October (JJASO), peaks in the boreal summer (i.e., June-August, JJA), and dips in the boreal autumn (i.e., September-November, SON). About $62 \%$ of the TCs that pass through EA happen in JJA while the remaining $38 \%$ occur in SON. More particularly, $93 \%$ of the total TC passages in EA during SON occur during the mature boreal autumn (September-October, SO) while only $7 \%$ or less than one TC passage is normally observed during the late boreal autumn (i.e., November).

In recent years, the EA region is marked by an escalated TCassociated cost of damages during the JJASO and SO (Fig. 1C). For example, the total TC-associated damages in EA reached US $\$ 23.5$ billion in SO 2019 where such amount can singlehandedly account for the $73 \%$ of the total TC-associated cost of damages for the entire JJASO 2019 (\$32.2 billion) (Fig. 1c) ${ }^{1,2}$. Expectedly, we found that there is a significantly increasing trend in the TC-associated cost of damages in EA during the SO $(p=0.001)$ (Table 1). Here we question whether such detected trend in TC-associated cost of damages is indicative of increasing activity of TCs in the EA region, particularly during the mature boreal autumn, and where such increasing signal can be attributed.

The rapid economic renaissance of the EA region propelled it as one of the most important global economic hubs, which contributes to more than $27 \%$ of the world's economy ${ }^{3,4}$. Therefore, impacts from natural hazards, including TCs, pose uncertainties not only to the lives and livelihood of people in the EA, but also to the global economy. As a matter of fact, the annual TC-associated cost of damages in the EA account to about $39 \%$ of the region's combined total annual cost of damages from hydrometeorological and climatological hazards, which corroborates that TCs are one of the most destructive natural hazards in the EA region ${ }^{1}$.

There is a wide gamut of available research on long-term TC variability in the entire WNP (Supplementary Table 1). Most of these studies have reported an abrupt decrease in WNP TC genesis in the mid- to late 1990s mostly due to unfavorable thermodynamic conditions for TC genesis such as increased vertical wind shear, stronger and intensified WNP subtropical high (WNPSH), and weakening of the Indo-Pacific warm pool linked with the cold central Pacific SST anomalies during the late 1990s to early $2000 s^{5-12}$. Meanwhile, there is a report of abrupt increase in the number of intense TCs in the WNP from 2006 to 2012 that is mostly contributed by the increase in TC intensity in September due to the positive low-level relative vorticity anomalies and the strengthening of the monsoon trough ${ }^{13}$. The varying regime shift years in these previous reports are mostly due to their differences in seasonal scaling and choice of time period. Some of the proposed reasons in the detected changes in TC characteristics in the WNP include the phase shifts in the Pacific Decadal Oscillation $(\mathrm{PDO})^{7,14}$ and Interdecadal Pacific Oscillation (IPO) ${ }^{15}$, and changes in the tropical and equatorial Pacific oceanic and atmospheric conditions $^{15}$, among others. However, in our succeeding discussion, we show that the TC studies drawn for the entire WNP are not necessarily applicable to the EA.

Meanwhile, there are only limited reports that focused on the EA region (Supplementary Table 2$)^{16-21}$. This is perhaps due to the considerably less TCs intersecting the EA region relative to the entire WNP. Furthermore, the existing literature on EA tends to cluster all TCs during the more active TC season (i.e., JJASON) ${ }^{16-19}$ further late in the TC season (e.g., October-December) ${ }^{11,12}$, and/ or combine all TCs in an annual basis ${ }^{20}$. Some of these previous reports show that there is an increasing trend in TC frequency and/or Power Dissipation Index (PDI) in EA in JJASO ${ }^{18}$. Additionally, an abrupt increase in TC landfall intensity from 1997 to 2008 in EA is found to be associated with the cooler SST anomalies in

\footnotetext{
Typhoon Research Center, Jeju National University, Jeju, South Korea. ${ }^{2}$ Philippine Atmospheric, Geophysical and Astronomical Services Administration, Department of Science and Technology, Quezon City, Philippines. ${ }^{3}$ These authors contributed equally: Joseph Basconcillo, Il-Ju Moon. ${ }^{凶}$ email: ijmoon@jejunu.ac.kr
} 


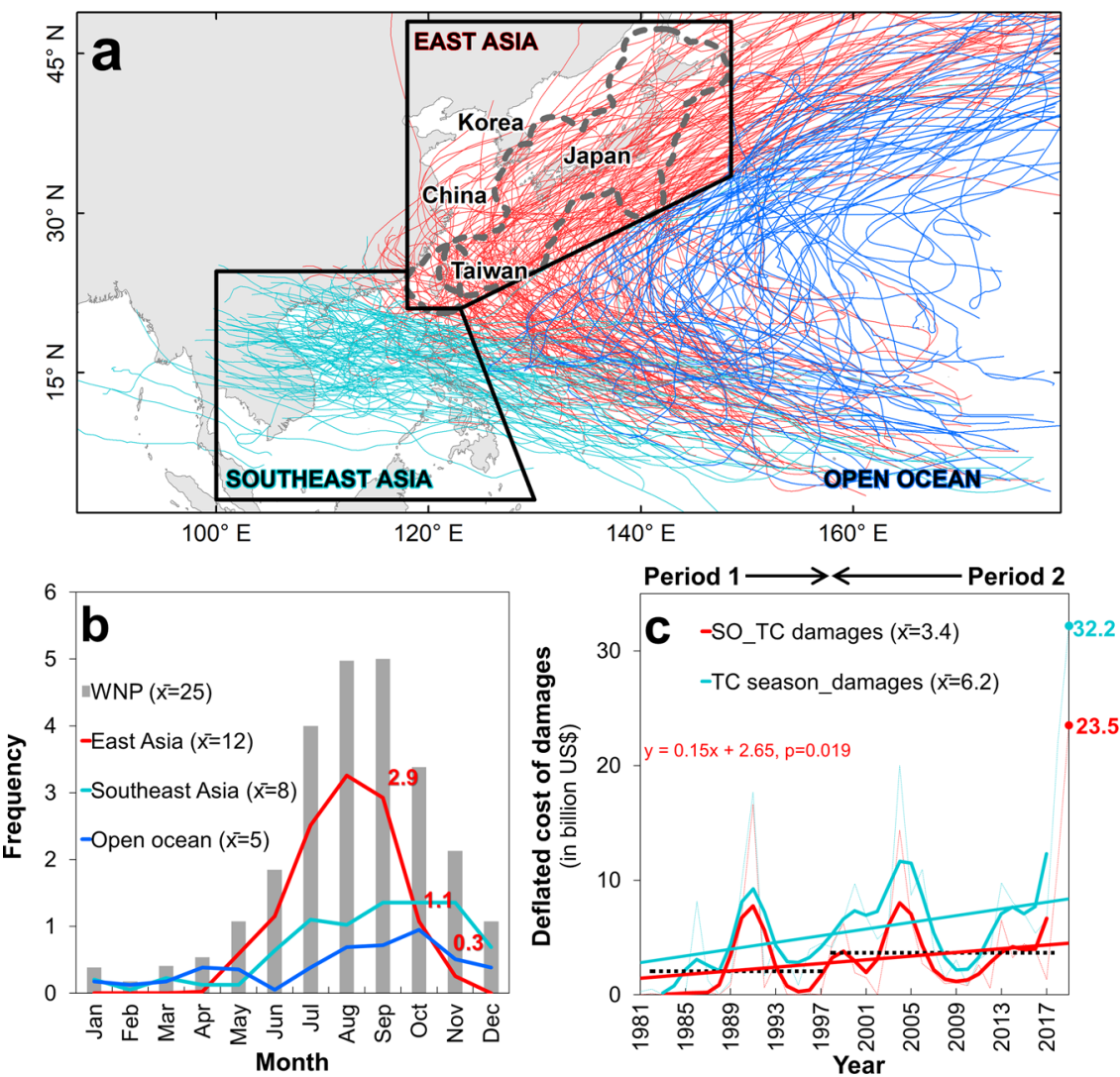

Fig. 1 Increasing cost of damages associated with tropical cyclones (TC) in East Asia (EA). a TC tracks during September-October (SO) in East Asia (red), Southeast Asia (cyan), and the open ocean (blue). The gray dashed lines represent the $225 \mathrm{~km}$ (175 km) buffer zone away from the nearest coastlines of Japan (Taiwan). b Mean monthly TC passage frequency in indicated domains. c TC-associated cost of damages in EA from June-October (cyan) and SO (red). The thick (thin) line represents the timeseries of the 1-3-4-3-1 filtered (raw) TC-associated cost of damages. The black dashed lines indicate the abrupt regime shift in mean TC-associated cost of damages during the Period 1 (1981-1997) and Period 2 (1998-2019), respectively. Significance is tested using student's t-test statistic with two-tailed distribution.

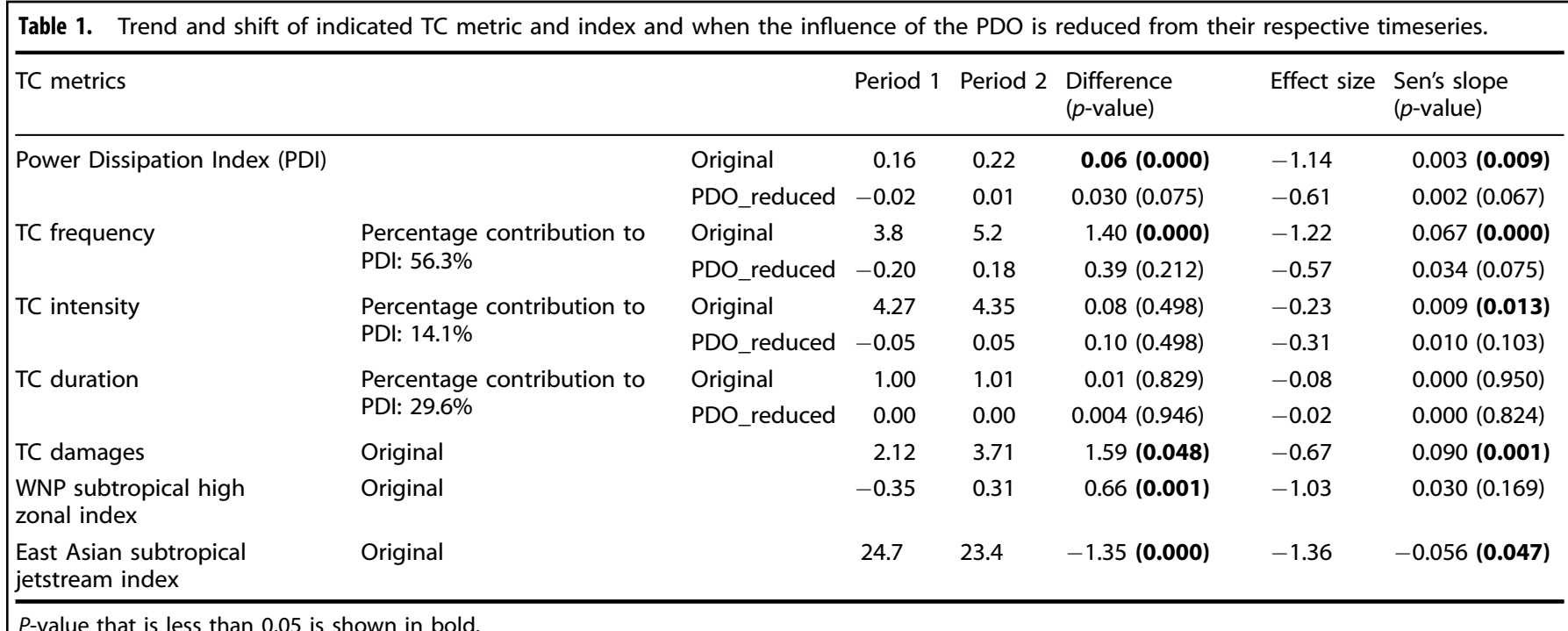

the tropical Pacific ${ }^{19}$. To the best of our knowledge, there is no existing study that exclusively focused on the SO in EA.

While our study appears to be closely related to a previous study that showed that there is an increasing PDI in Korea and Japan from September 1 to 20 (i.e., early boreal autumn) ${ }^{21}$, we deviate from their reported conclusion on the PDI component that contributed to the increasing long-term trend in activity of TCs in EA during the SO. Additionally, we also report a significant abrupt increase in PDI in EA during the SO. Such abrupt change is not found in the said previous report ${ }^{21}$. Lastly, through seasonal 

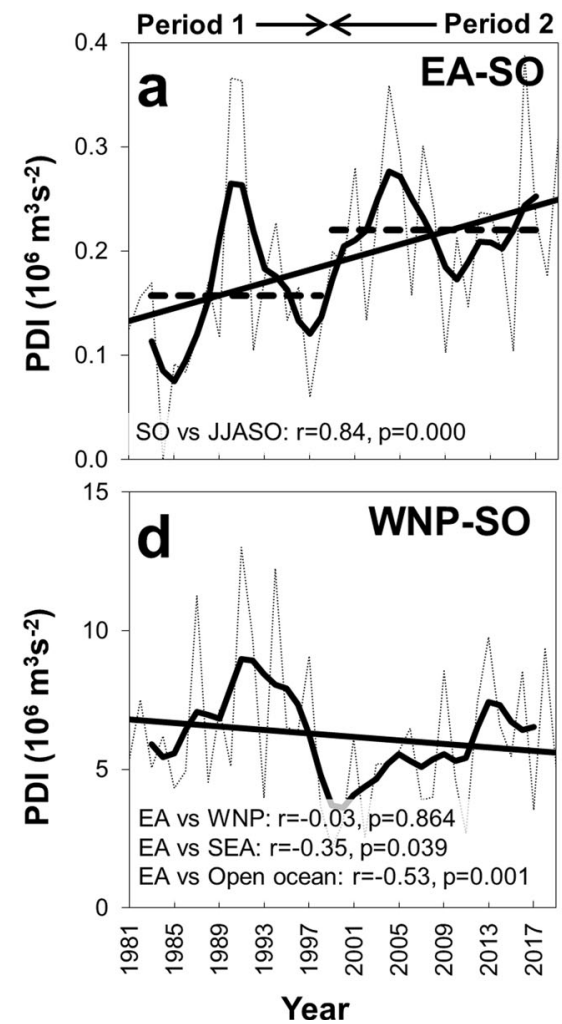
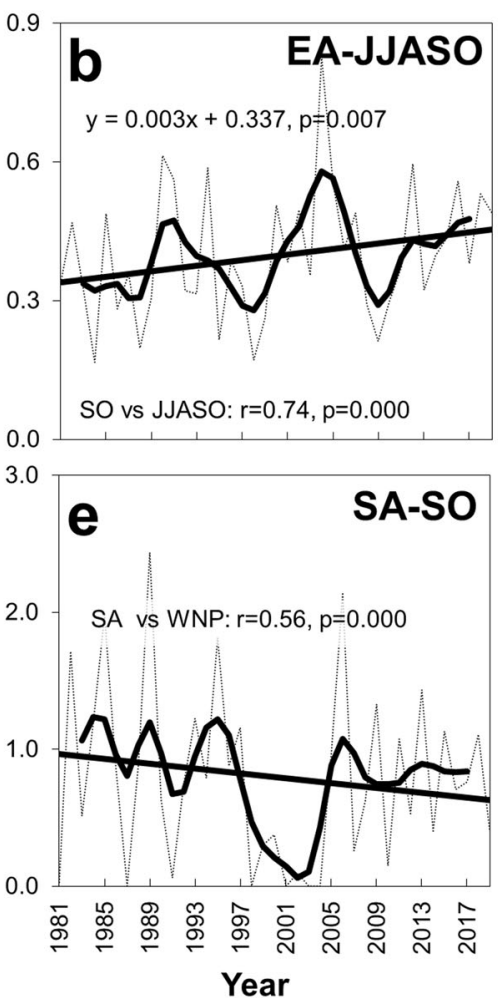
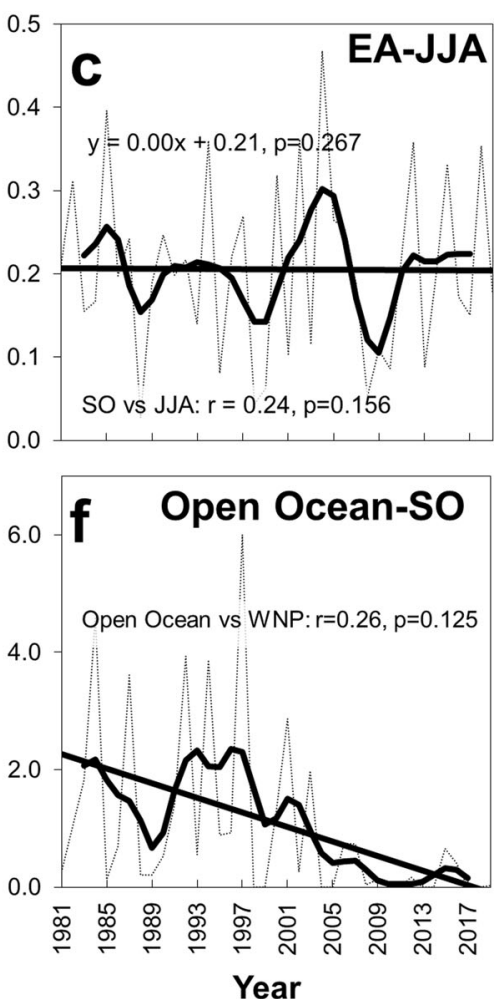

Fig. 2 Increasing activity of tropical cyclones in East Asia during the mature boreal autumn. a-c Timeseries of Power Dissipation Index (PDI) in East Asia (EA) during September-October (SO), June-October (JJASO), and June-August (JJA), respectively. d-f Timeseries of PDI during the SO in the Western North Pacific (WNP), Southeast Asia (SA), and in the open ocean, respectively. The thick (thin) line represents the timeseries of the 1-3-4-3-1 filtered (raw) PDI. In a the black dashed lines indicate the abrupt regime shift in PDI during the Period 1 (1981-1997) and Period 2 (1998-2019), respectively. Significance is tested using student's t-test statistic with two-tailed distribution.

decomposition, we present evidence that the TC studies done in JJA are not necessarily applicable to the TC variability in SO.

With the growing impetus to understand the long-term variability of TCs and their impact, here we provide discussion on the robust observational evidence of increasing long-term activity of TCs in EA in the succeeding discussions. We emphasize that our aim is to contribute to the existing knowledge pool in understanding long-term TC variability in EA rather than to discount the merits of previous reports.

\section{RESULTS}

\section{Abrupt regime shift in the activity of tropical cyclones in East Asia}

The PDI is a wind speed index based on the cubed of the maximum sustained winds of a TC at six-hourly interval over its lifetime and is widely used to estimate the TC destructive potential or activity ${ }^{22,23}$. In this section, we first calculated the PDI in EA during SO to investigate changes in long-term TC activity. Here we show a significantly increasing long-term trend in PDI $(p=0.009)$ and an abrupt increase in mean PDI in SO during the Period 2 $(1998-2019, \bar{x}=0.22)$ when compared with Period 1 (1981-1997, $\bar{x}=0.16, p=0.000$ ) (Fig. 2a and Table 1). Such trend and shift in $\mathrm{PDI}$ during the SO is similar to the significantly increasing trend $(p=0.002)$ and abrupt increase in TC-associated cost of damages during the Period 2 ( $\bar{x}=$ US\$ 3.7 billion) compared with Period 1 $(\bar{x}=$ US\$ 2.1 billion; $p=0.048$ ) (Fig. 1c and Table 1).

To investigate the intraseasonal variability of TC activity in EA, we additionally calculated the PDI in EA during JJASO and JJA. The result shows a significant uptrend in PDI in JJASO $(p=0.007)$ while there is no significant trend in PDI in JJA (Fig. 2b, c). We also found that there is no significant correlation between PDI in JJA and in
SO (Fig. 2c). These imply that the recent increase in TC activity in EA and the associated cost of damages is mainly due to the increased TC activity in SO, which is yet another reason why seasonal scaling is a considerable concern in TC variability studies.

Our concern on spatial scaling is explained by showing that the TC activity indicated by PDI in the EA, particularly in SO, has a diverging trend and no significant correlation with the TC activity in WNP ( $r=-0.03)$ (Fig. 2d). This indicates that the TC variability studies made for the WNP in SO may not necessarily be applicable for the EA region. However, the TC activity in the WNP in SO has a significant correlation in Southeast Asia $(r=0.56, p=0.000)$ (Fig. 2e), which suggests that the TC variability in the WNP is likely applicable in the said region. Meanwhile, the PDI in EA during the SO is significantly anticorrelated with PDI in Southeast Asia $(r=-0.35, p=0.039)$ and open ocean $(r=-0.53, p=0.001)$, respectively, which further corroborates that there is a prominent intrabasin variability within the WNP (Fig. 2d, e).

The PDI can be decomposed into its three components: TC frequency, intensity, and duration (Fig. $3 a-c)^{23}$. The TC frequency refers to the number of TCs that passed through EA. The TC intensity is the mean intensity of TCs while they are in EA. The TC duration is the total velocity-weighted duration of TCs while they are in EA. Of these components, the TC passage frequency has the highest percentage contribution to the total PDI variance at $56.3 \%$ while the TC intensity and TC duration can only explain 14.1 and $29.6 \%$ of the total PDI variance, respectively (Table 1). Additionally, there is a detected abrupt shift in TC passage frequency during the Period $2(p=0.000)$ while there is no significant abrupt shift in both TC intensity and duration during the Period 2, which imply that the detected abrupt shift in the PDI during the Period 2 is attributed with the increased TC passage frequency in EA (Table 1). 

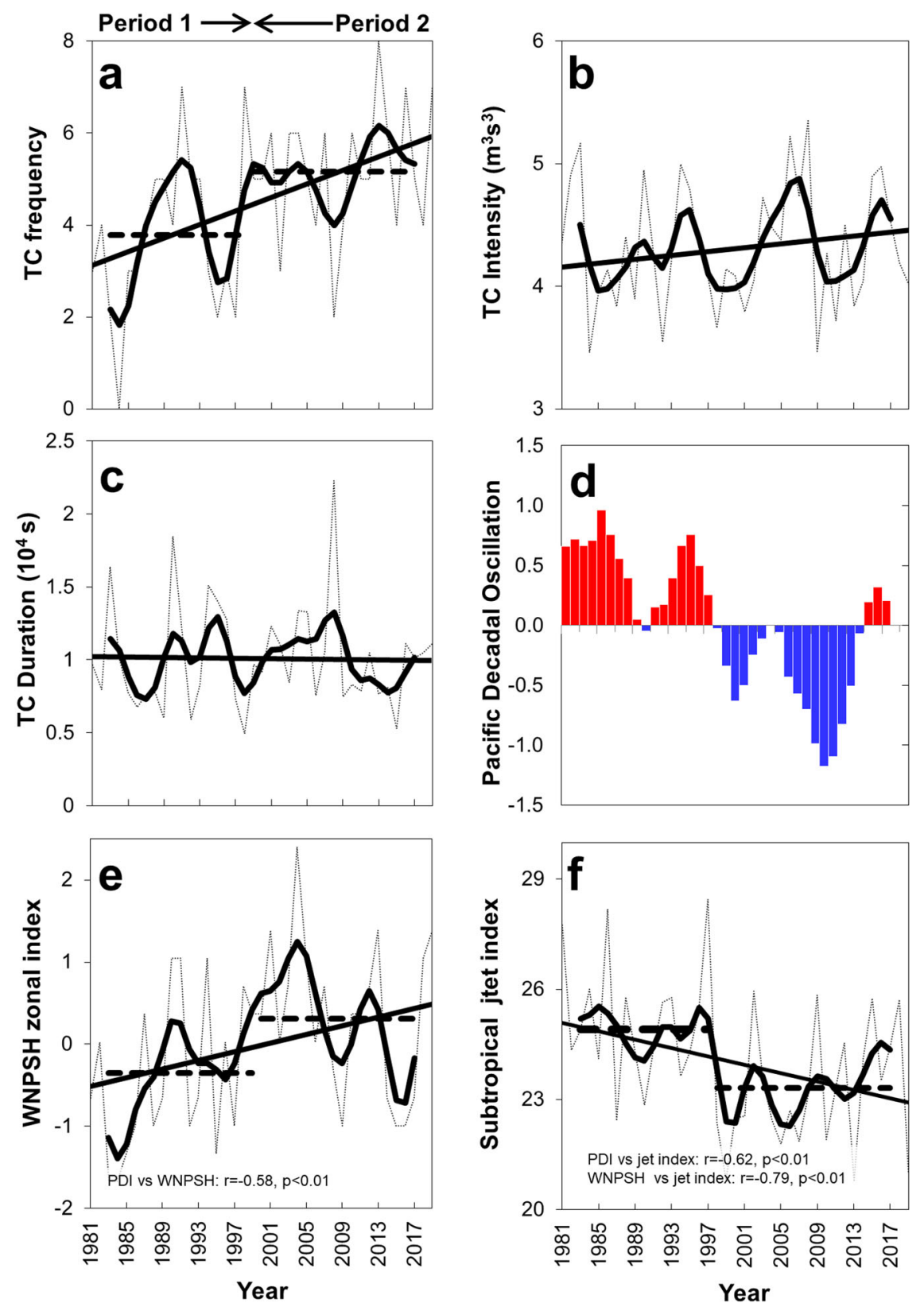

Fig. 3 Components of the Power Dissipation Index (PDI) in East Asia (EA) during the mature boreal autumn. a-c Timeseries of the indicated components of PDI in EA. d Timeseries of the 5-year running centered mean of the Pacific Decadal Oscillation (PDO). e, $\mathbf{f}$ Timeseries of the Western North Pacific subtropical high zonal index and East Asian subtropical jet index, respectively. In a-c, e, f, the thick (thin) line represents the timeseries of the 1-3-4-3-1 filtered (raw) timeseries, respectively. In a, e, f, the black dashed lines indicate the abrupt regime shift in PDI during the Period 1 (1981-1997) and Period 2 (1998-2019), respectively. Significance is tested using student's t-test statistic with twotailed distribution.

We deviate from a previous study that reported a significantly increasing TC duration during the early boreal autumn ${ }^{21}$, which is perhaps due to our differences in the definition of seasonal and spatial scaling. However, we found a significant abrupt increase in TC intensity from 2003 to $2019(p=0.003)$, which is parallel to another previous study done in the WNP ${ }^{13}$. Such finding merits future investigation.

For these reasons, we come in full circle to confirm that the long-term trend and abrupt increase in TC passage frequency in EA in SO can explain the abrupt regime shift and the increasing trend in activity of TCS in the EA region more than the other PDI components. Nonetheless, we emphasize that the TC intensity has a significant increasing trend $(p=0.013)$ (Table 1$)$ and its combined percentage contribution together with the TC duration account to almost half of the PDI variance (43.7\%), which means that any changes in these two PDI components could potentially reflect in the long-term PDI variability.

\section{Large-scale environment that influences tropical cyclone variability in East Asia}

To highlight the large-scale environment that influences TC passage frequency in EA in SO, we plotted the composite difference maps between Period 2 and Period 1 (Fig. 4a-d). Most of the significant increase in TC passage frequency in EA during the Period 2 are found to the east of Taiwan heading 


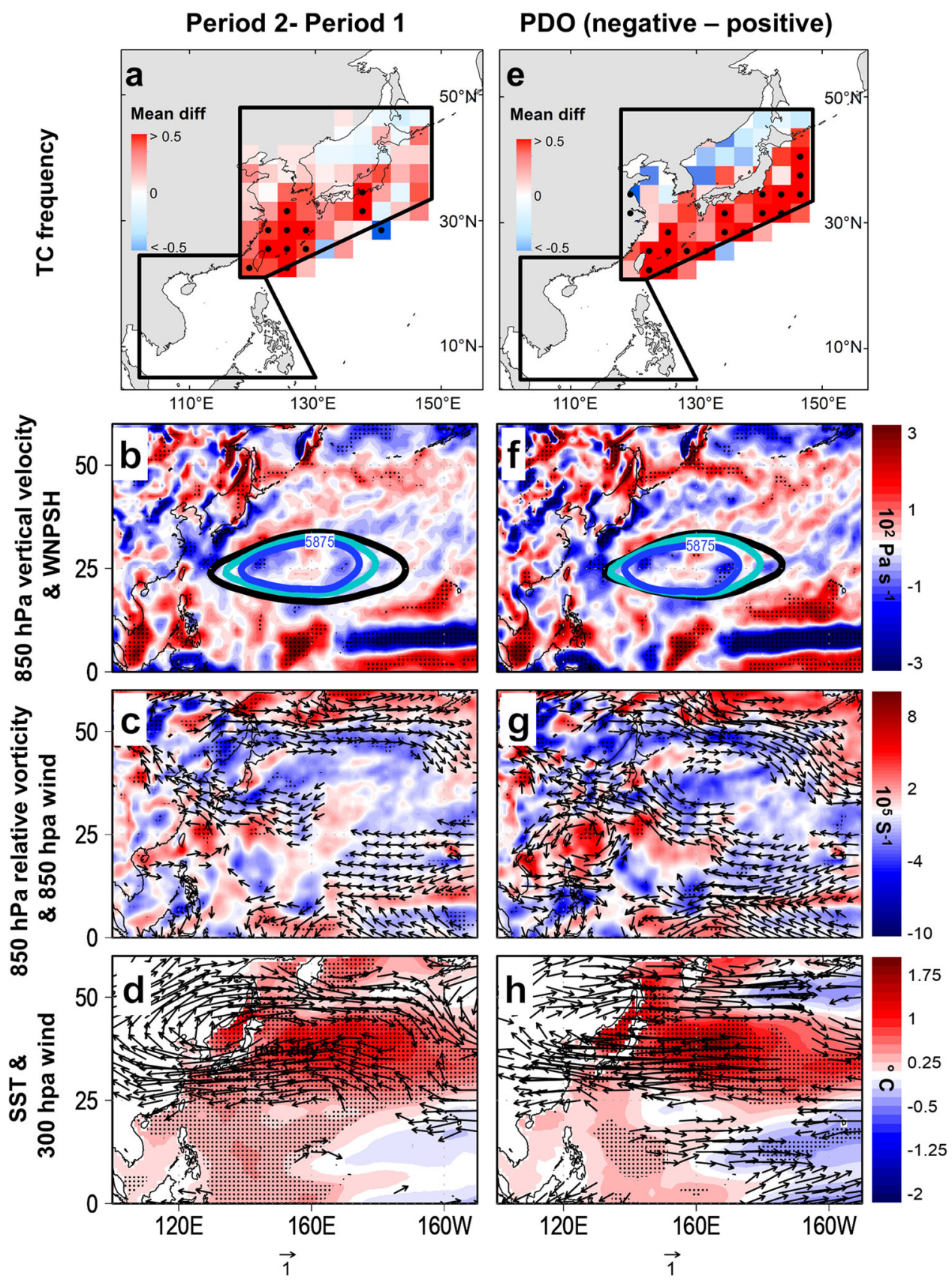

Fig. 4 Composite difference maps in the large-scale environment during the mature boreal autumn. The composite difference of largescale environment between the Period 2 and Period 1 (left panel), and positive and negative PDO phase (right panel) for a, e tropical cyclone passage frequency, b, f $850 \mathrm{hPa}$ pressure vertical velocity, $\mathbf{c}, \mathbf{g} 850 \mathrm{hPa}$ relative vorticity (shaded) and $850 \mathrm{hPa}$ wind (vector), and d, h sea surface temperature (shaded) and $300 \mathrm{hPa}$ wind (vector) In $\mathbf{a}-\mathbf{h}$, the black dots represent significant difference at $p<0.05$. In $\mathbf{b}, \mathbf{f}$, the (black) blue and cyan lines represent the (climatological) location of the Western North Pacific subtropical high $(=5875 \mathrm{gpm})$ during Period 1 and Period 2, respectively. In $\mathbf{c}, \mathbf{g}$, the $850 \mathrm{hPa}$ relative vorticity is multiplied with 1,000,000 for scaling. Significance is tested using student's t-test statistic with two-tailed distribution.

northward via Okinawa (Fig. 4a). Meanwhile, some of the significant changes in the large-scale environment during the Period 2 when compared with Period 1 include the stronger low-level westerlies over the Philippines and stronger easterlies that converged into an anomalous cyclonic vorticity in the vicinity of Okinawa (Fig. 4c). The WNP subtropical high (WNPSH) acts as a gatekeeper of TC passages in $\mathrm{EA}^{16,24}$ where its expansion enhances westward intrusion (Fig. 4b) of increased north-south orientation of contiguous cyclonic vorticity (Fig. 4c) and the westward intrusion of the environmental steering flow (Fig. $5 \mathrm{a}-\mathrm{C}$ ), which steers the increased TC passages in $E A^{5,16,24-26}$. This is further corroborated by the significant increase in the WNPSH zonal index ${ }^{25}$ (Fig. 3e). A positive WNPSH zonal index means westward displacement and intrusion of the WNPSH. The parallel anomalous easterlies at 850 and $300 \mathrm{hPa}$ levels in EA (Fig. 4c, d) indicate a weak vertical wind shear (Supplementary Fig. 1a) in the region where the significant increase in TC passages during the Period 2 are also detected. Since the PDI in the WNP is not significantly correlated with the PDI in EA in SO, the role of a weak wind shear is perhaps more important to sustain the TC intensity and duration over the TC lifetime are in EA. 

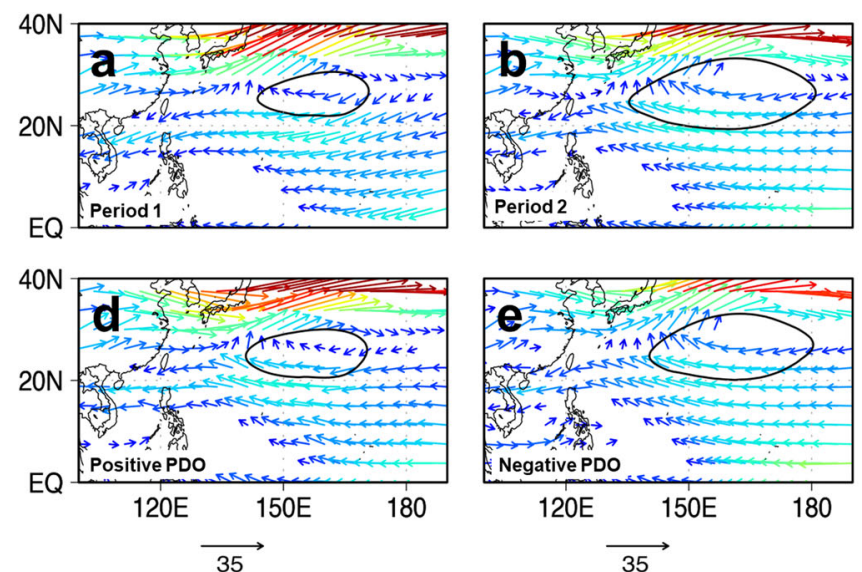

35
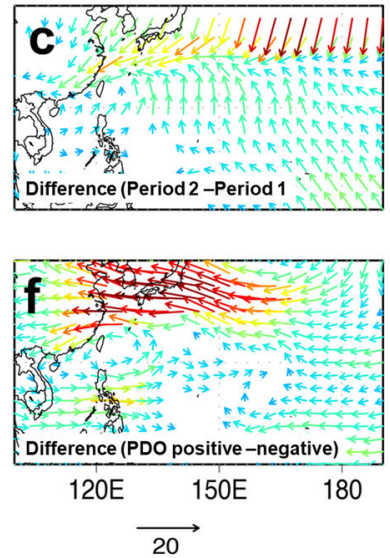

20

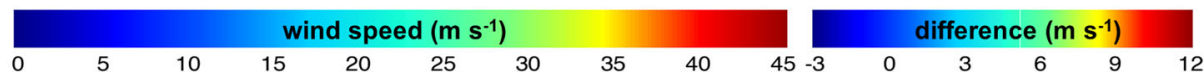

Fig. 5 Integrated environmental steering flow from 850 to $500 \mathrm{hPa}$ in the Western North Pacific (WNP) during the mature boreal autumn. a-c Mean 850-500 hPa steering flow during the Period 1 (1981-1997) and Period 2 (1998-2019), and their difference, respectively. d-f Mean 850-500 hPa steering flow during the positive and negative PDO phases, and their difference, respectively. In a, $\mathbf{b}$ and $\mathbf{d}$, e, the black contour indicates the position of the WNP subtropical high $(=5875 \mathrm{gpm})$ during the indicated period.
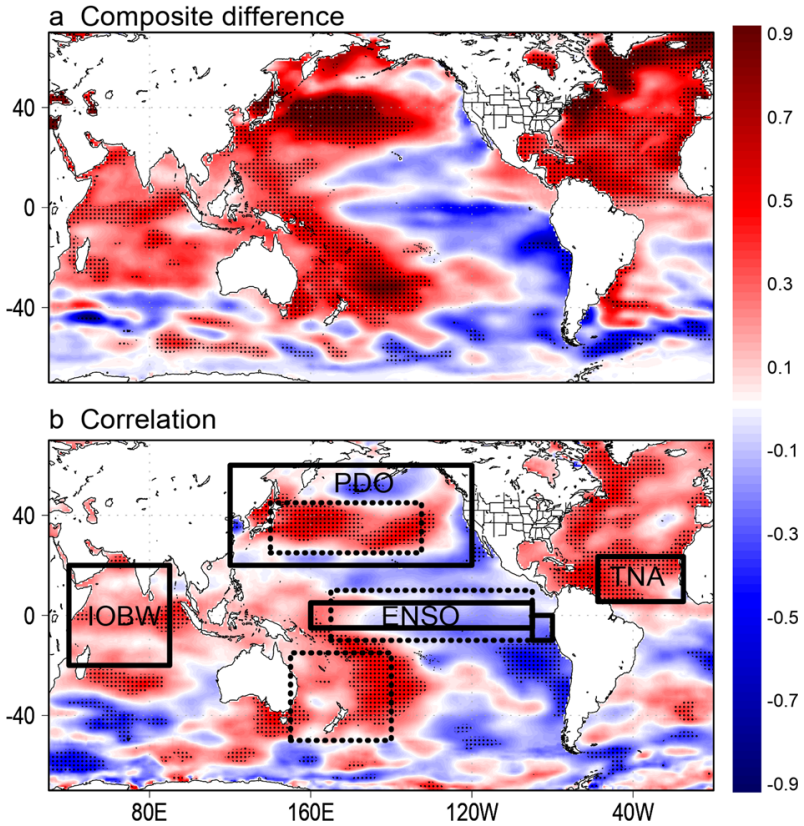

Fig. 6 Relationship of sea surface temperature (SST) and tropical cyclone (TC) passage frequency in East Asia during the mature boreal autumn. a Global composite difference map of SST between Period 2 (1998-2019) and Period 1 (1981-1997), respectively. b Spatial correlation map of TC passage frequency and SST. The black solid (dotted) boxes indicate the locations of indicated climate index (Interdecadal Pacific Oscillation regions). In a, $\mathbf{b}$, the black dots indicate significant difference and correlation at $p<0.05$, respectively. Significance is tested using student's t-test statistic with twotailed distribution.

The East Asian subtropical jetstream is stalled and weakened by the anomalous upper-level easterlies along the contiguous warm North Pacific SST anomalies (Figs. 4d and 6a), which consequentially encourages the northward and westward shifts of WNPSH. Such relationship is explained by the significant weakening of the East Asian subtropical jetstream index ${ }^{27}$ during the Period 2 (Fig. 3f). We note the significant correlation between the East Asian subtropical jetstream index and the WNPSH zonal index $(r=-0.79, p=0.000)$, which means that when the WNPSH is westward-displaced the East Asian subtropical jetstream tends to be weak.

To determine the influence of SST climate modes to TC passage frequency in EA, we plotted their spatial correlation. We did not find a significant correlation between TC passage frequency in EA with all the classic Niño flavors (e.g., Niño 4, Niño 3, Niño 3.4, Niño $1+2$ ) (Fig. 6b) implying that the El Niño Southern Oscillation (ENSO) has minimal role in influencing the interannual TC passage frequency variability in EA. We also note that the Niño 4 index ${ }^{28}$, being the closest classic ENSO index to the WNP, is not significantly correlated with TC passage frequency in EA $(r=0.29)$. A number of previous studies linked ENSO with TC variability in the WNP ${ }^{7,14,17}$ but it appears that this cannot be said true for the EA in SO.

However, there are widespread significant spatial correlations between TC passage frequency and SST in many parts of the subtropical North and South Pacific Ocean, subtropical North Atlantic Ocean, and tropical Indian Ocean (Fig. 6b). The areas with significant correlation with TC passage frequency correspond with the location of known SST-based climate indices ${ }^{28,29}$ such as the PDO, IPO, the Tropical North Atlantic (TNA) SST, and the Indian Ocean Basin Wide SST (IOBW) (Supplementary Fig. 2a-c). The PDO and IPO are long-term SST modes while the TNA and IOBW are interannual SST modes. The PDO and IPO have both shifted to their negative phase in the mid-1990s while the IOBW has generally more positive phases in the same period. Among these climate modes, the PDO has the highest correlation with the TC passage frequency $(r=-0.60, p=0.001)$ followed by the TNA $(r=$ $0.54, p=0.001)$, and IPO $(r=-0.44, p=0.016)$ (Table 2), which suggest that the PDO has the biggest influence on the variability of TC passage frequency in the EA region among these SST modes. Meanwhile, the IOBW is not significantly correlated with TC passage frequency.

To further confirm whether the PDO has the highest contribution among the two other SST modes (i.e., TNA, IPO), we calculated for their partial correlation with TC passage frequency in EA in SO while controlling for PDO (Table 2). When PDO is controlled, the partial correlation of TC passage frequency and TNA and IPO becomes insignificant. When TNA is controlled, the PDO remains significantly correlated with TC passage frequency $(r=-0.43, p=0.011)$ while the correlation of IPO becomes insignificant. When IPO is controlled, the partial correlations of both PDO $(r=-0.49, p=0.003)$ and TNA 


\begin{tabular}{|c|c|c|c|c|}
\hline \multicolumn{5}{|c|}{ Partial correlation } \\
\hline Control & $\begin{array}{l}\text { Bivariate } \\
\text { correlation }\end{array}$ & Variable & TNA & IPO \\
\hline \multirow[t]{2}{*}{ PDO } & $-0.60(\mathbf{0 . 0 0 0 )}$ & $\begin{array}{l}\text { TC passage } \\
\text { frequency }\end{array}$ & $0.31(0.070)$ & $\begin{array}{l}0.22 \\
(0.203)\end{array}$ \\
\hline & & & PDO & IPO \\
\hline \multirow[t]{2}{*}{ TNA } & $0.54(\mathbf{0 . 0 0 1 )}$ & $\begin{array}{l}\text { TC passage } \\
\text { frequency }\end{array}$ & $\begin{array}{l}-0.43 \\
(\mathbf{0 . 0 1 1 )}\end{array}$ & $\begin{array}{l}-0.20 \\
(0.264)\end{array}$ \\
\hline & & & PDO & TNA \\
\hline IPO & $-0.44(\mathbf{0 . 0 0 7 )}$ & $\begin{array}{l}\text { TC passage } \\
\text { frequency }\end{array}$ & $\begin{array}{l}-0.49 \\
\mathbf{( 0 . 0 0 3 )}\end{array}$ & $\begin{array}{l}0.39 \\
(\mathbf{0 . 0 2 4 )}\end{array}$ \\
\hline IOBW & $0.21(0.229)$ & $\begin{array}{l}\text { TC passage } \\
\text { frequency }\end{array}$ & & \\
\hline \multicolumn{5}{|c|}{ Percentage contribution } \\
\hline & \multicolumn{2}{|c|}{$\begin{array}{l}\text { Standardized linear regression } \\
\text { coefficient }\end{array}$} & \multicolumn{2}{|c|}{ Percentage contribution } \\
\hline PDO & \multicolumn{2}{|l|}{-0.86} & \multicolumn{2}{|l|}{$49 \%$} \\
\hline TNA & \multicolumn{2}{|l|}{0.37} & \multicolumn{2}{|l|}{$21 \%$} \\
\hline IPO & \multicolumn{2}{|l|}{0.53} & \multicolumn{2}{|l|}{$30 \%$} \\
\hline
\end{tabular}

$(r=0.39, p=0.024)$ with TC passage frequency remain significant, respectively. We also computed the standardized linear regression coefficient of the PDO, TNA, and IPO with TC passage frequency to compute for their respective percentage contributions to TC passage frequency. We found that the PDO, TNA, and IPO contribute to 49,21 , and $30 \%$ to the regressed TC passaged frequency, respectively. The partial correlation and percentage contribution of PDO corroborate that it has the biggest influence to TC passage frequency in EA during the SO.

\section{Linkage with the Pacific Decadal Oscillation}

The PDO is typically measured using the leading principal component of monthly SST north of $20^{\circ} \mathrm{N}$ in the Pacific Ocean. The PDO exists in all months ${ }^{30}$, which means that even though its influence is largely expressed in interdecadal scale, it remains to influence interannual climate variation. With its known periodicity of about $15-25$ years and $50-70$ years ${ }^{31,32}$, the PDO has recently shifted to its negative phase in the mid-1990s [Fig. 3d]. A negative PDO phase is characterized by warm SST anomalies in the subtropical North Pacific while a contrasting pattern is typically observed in a positive PDO phase.

The associated changes in the large scale environment with the variability of PDO are similar with the composite difference maps in the large scale environment between Period 2 and Period 1 (Fig. $4 a-h)$. These differences include more TC passages in most parts of East Asia [Fig. 4e] that are driven by the north-south dipole of contiguous anomalous cyclonic vorticity, anomalous convective activities, stronger WNP subtropical high, weaker East Asian subtropical jetstream (Fig. $4 \mathrm{f}-\mathrm{h}$ ), and westward intrusion of the environmental steering flow (Fig. $5 d-f$ ),

The stalling of the East Asian subtropical jetstream warms the subtropical WNP SST via two possible mechanisms. First, the weakening and the northward displacement of the subtropical jetstream allow increased meridional transport of tropical heat to the midlatitudes thereby increasing surface temperature in the midlatitudes. This is because the subtropical jetstream is closely related to the poleward boundary of the Hadley Circulation where an increased sinking motion consequently increases surface

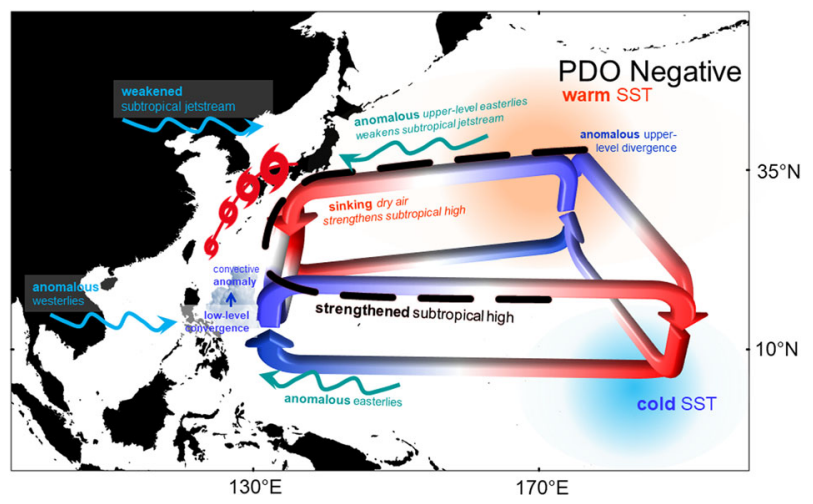

Fig. 7 Influence of the Pacific Decadal Oscillation to tropical cyclone (TC) variability in East Asia during the mature boreal autumn. The arrows indicate the direction of the circulation while the blue (red) color represents low (high) pressure regions. A negative PDO phase, characterized by warm sea surface temperature (SST) in the North Pacific, is associated with increased rising motion, anomalous upper-level divergence, and anomalous upperlevel easterlies. The risen upper air zonally flows westward and descends as dry air, which prompts the strengthening and westward extension of the Western North Pacific subtropical high (WNPSH). In addition, the said upper-level easterlies collides and stalls the upperlevel westerlies associated with the subtropical jetstream, which results to further SST warming in the North Pacific. The weakened and stalled subtropical jetstream retreats northward allowing an expanded WNPSH. Meanwhile, the low-level convergence of anomalous westerlies and easterlies to the east of the Philippines prompts the rise of convective anomalies where it meridionally descends as dry air in the midlatitudes, which also strengthens the WNPSH. In the zonal direction, the risen air flows eastward and descends in the cold SST region in the eastern equatorial Pacific. In the meridional direction, the sunken dry air meridionally rises in the warm North Pacific SST. The strengthened WNPSH and northwarddisplaced jetstream result to a favorable steering environment that allows tropical cyclones to pass in the EA region.

temperatures in the midlatitudes ${ }^{33}$. The second mechanism is mostly related to the stalling of the subtropical jetstream flow. When the subtropical jetstream flow is stronger, the strengthened westerlies enhances the vertical mixing of ocean water in the North Pacific, which cools the ocean surface. In contrast, when the subtropical jet weakens, the vertical mixing slows down, which warms the ocean surface ${ }^{34}$.

We reduced the linear influence of PDO from the timeseries of TC passage frequency. After such collinearity reduction, the trend of the TC passage frequency becomes insignificant, and the difference of mean values of the TC passage frequency between Period 2 and Period 1 also becomes effectively insignificant (Table 1). Similar results are found when we reduced PDO from the PDI timeseries. We further note that there is no significant correlation between PDO and TC intensity $(r=0.06)$, and TC duration $(r=-0.06)$, respectively. As such, there is no corresponding abrupt change in their respective timeseries after reducing their collinearity with PDO (Table 1).

The influence of the PDO to the TC passage frequency in the EA region works via two routes-the subtropical WNP and tropical WNP in the zonal and meridional directions (Fig. 7). The warm sea surface temperatures in the North Pacific result in increased rising motion (Fig. 4f), anomalous upper-level divergence, and anomalous upper-level easterlies (Fig. $4 \mathrm{~h}$ ). A positive pressure vertical velocity (red shade) means sinking motion while a negative pressure vertical velocity (blue shade) indicates rising motion (Fig. 4f). The risen upper air in the North Pacific flows westward and meridionally descends equatorward as dry air, which prompts the strengthening and westward extension of the WNPSH. Additionally, the said upper-level easterlies collides and stalls 
the East Asian subtropical jetstream that also results to weaker vertical mixing of ocean water, which is related to warmer North Pacific SST ${ }^{34,35}$ (Figs. $4 \mathrm{~h}$ and $6 \mathrm{a}$ ). The weakened and stalled subtropical jetstream also retreats northward allowing an expanded WNPSH and increased transport of tropical heat to the midlatitude.

Meanwhile, the low-level convergence of anomalous westerlies and easterlies in the tropical WNP (Fig. 4g) prompts the rise of convective anomalies that consequently and meridionally descends poleward (the northward displace subtropical jetstream allows increased tropical heat transport), which further strengthen the WNPSH. In the zonal direction, the risen air flows eastward and descends in the cold SST region in the eastern equatorial Pacific (Fig. 4h). In the meridional direction, the sunken dry air eventually rises in the warm North Pacific Ocean surface. The combination of strengthened WNP subtropical high and a northward-displaced subtropical jetstream ultimately results to a favorable steering environment that allows TCs to pass in the EA region.

\section{Extended temporal analysis of TC passage frequency}

Given that the PDO is a long-term mode of climate variability, another concern that has to be addressed is the limited temporal coverage of our main analysis period (i.e., 1981-2019). We extended our analysis of TC passage frequency to cover the period 1951-2019 and results show that the significant correlation of PDO and extended TC passage frequency persists $(r=-0.40, p=$ 0.001 ), which suggests that our findings remain applicable even in an extended temporal coverage. However, such lower correlation is due to the low interannual covariability of the PDO and TC passage frequency before 1981, which is perhaps an artifact of unreliable TC data during the pre-satellite period ${ }^{36,37}$. In the absence of satellite observations, the reliability of TC passage frequency based on TC intensity classification cannot be free from the issue of data unreliability.

Using the detected periodicity in PDI and TC passage frequency (Supplementary Fig. $3 a-d$ ), we decomposed the timeseries of the extended standardized TC passage frequency to isolate its temporal components (Fig. $8 a-d$ ). We found that there is a considerably higher anticorrelation between the PDO and the periodic component $(r=-0.87, p=0.000)$, and trend component $(r=-0.70, p=0.000)$ of the extended standardized TC passage frequency, respectively. These correlations robustly confirm the influence of the PDO to TC passage frequency that is largely tied in the interdecadal scale. Meanwhile, the random components of standardized TC passage frequency and PDO is not significantly correlated with each other.

Recognizing that the TC passage frequency has the largest percentage contribution in PDI during SO in EA from 1981 to 2019 (Table 1) then it is likely that the detected increasing activity of TCs in EA will fluctuate according to the shifts in PDO phases. Therefore, the increasing activity of TCs in EA during the mature boreal autumn is linked to long-term climate variability.

\section{DISCUSSION}

One of the outstanding challenges in regional disaster risk reduction is the integration of knowledge management and establishment of regional disaster reduction cooperation hubs. Considering the impetus of our findings on the increasing activity and escalating cost of damages associated with TCs in EA, it is, perhaps, high time to open discussions on institutionalizing regional disaster cooperation centers in the EA region, and/or enhance the mandates of the existing knowledge management hubs in EA like the Asia-Pacific Economic Cooperation Climate Center and the Regional Specialized Meteorological Center-Tokyo to include regional disaster reduction cooperation, and/or further explore the potential of the academic community.

Our report does not make explicit attribution to global warming on the increasing activity of TCs in EA but it also does not mean that we are in opposition of such attribution. We need to underscore that the trend and periodic components of the extended TC passage frequency have significant anticorrelation with PDO [Fig. 8b, c) indicating that the detected increasing longterm trend and abrupt increase in the activity of TCs in EA is likely a reflection of long-term climate variability, particularly to the shifts in PDO phases. Long as we are constrained by limited historical TC observations, statistical constructs of physical systems (i.e., PDO is defined as the leading principal component of SST in the North Pacific), and the inability of some global models to
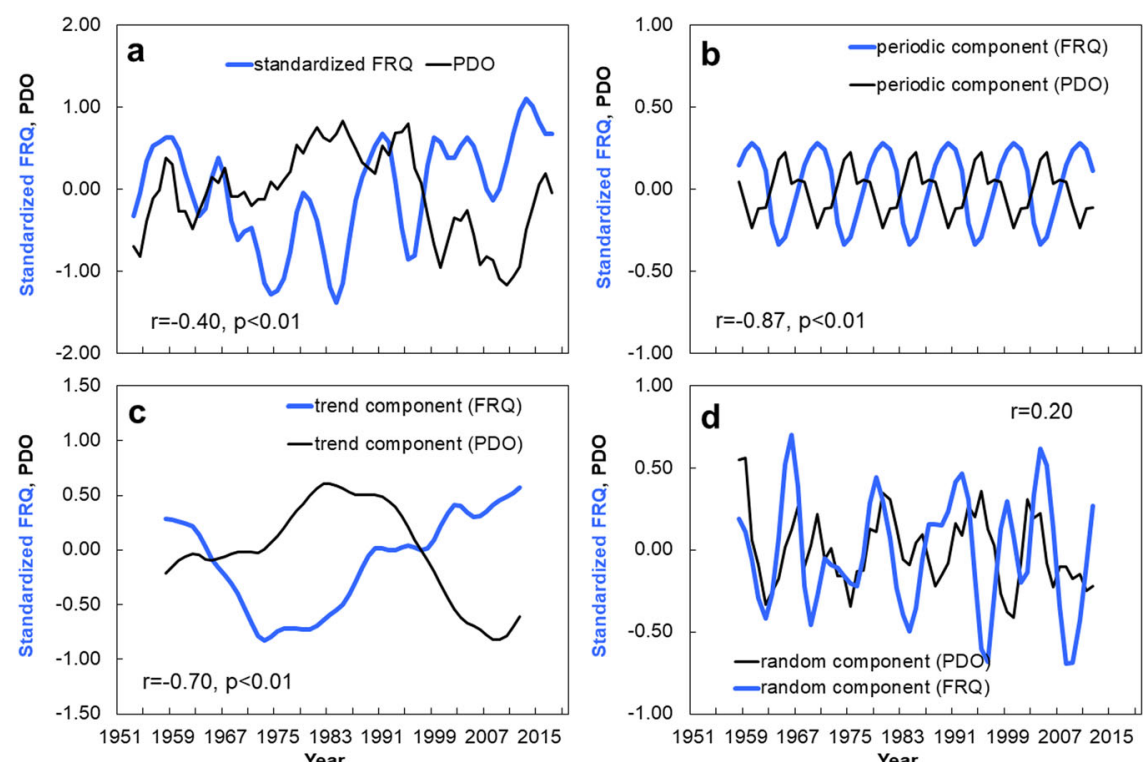

Fig. 8 Temporal decomposition of the extended tropical cyclone (TC) passage frequency during the mature boreal autumn from 1951-2019. a The blue and black line represents the timeseries of the standardized TC passage frequency (FRQ) and the Pacific Decadal Oscillation (PDO), respectively. $\mathbf{b}-\mathbf{d}$ Same with a but shows the periodic, trend, and random components of the standardized FRQ and PDO, respectively. In $\mathbf{a}-\mathbf{d}$, the inset correlation coefficients show the correlation of the raw and decomposed standardized FRQ components and PDO. Significance is tested using student's t-test statistic with two-tailed distribution. 
properly capture the tropical-extratropical interactions in the $\mathrm{PDO}^{38,39}$ then projecting the future TC activity in EA remain unclear. However, it should also be noted that recent global models show significant improvement in simulating the tropicalextratropical manifestations of $\mathrm{PDO}^{40}$, which may allow future studies on similar subject to perform numerical simulations of interaction between PDO and TC activity in EA.

We further note that the Atlantic Multidecadal Oscillation (AMO) is concluded (by the same scientists who practically discovered it) to be externally driven by volcanic forcing rather than the original thought that it is a naturally oscillatory system. Volcanic particulate matters cool the atmosphere while greenhouse gases warm the atmosphere. With the lagged synchronicity of immediate past large volcanic eruption to AMO cycle, it is hypothesized that the current positive AMO phase is linked with greenhouse gases warming ${ }^{41,42}$. Such new findings on the absence of multiyear oscillations in the North Atlantic have farwide implications, especially to TC variability studies. For example, if such report is held true, then it is also likely that the increased and increasing activity of TCs in EA in SO may be attributed with anthropogenic greenhouse gases warming because the AMO is significantly correlated with TNA $(r=0.94, p=0.000)$ and PDO $(r=-0.71, p=0.000)$, respectively. In addition, the abrupt shifts in TC passage frequency appear to coincide with the shifts of the TNA from its negative to positive phase in the mid-1990s (Supplementary Fig. 2a). It is, therefore, a considerable concern whether the PDO is also linked with greenhouse gases warming rather it is being an internally oscillatory system. A paleoclimatological analysis of fossilized phytoplankton in the last 2.7 millennia shows coincident variability of ENSO and PDO ${ }^{43}$. They also showed that there are evidence of lack of synchronism between the timing of large volcanic eruptions and large PDO events in the last 2,500 years, which imply that the PDO is not externally driven, at least by volcanic eruptions. However, given our current limitation of understanding statistically constructed and historically observed SSTs in the North Pacific, studies such as ours should be regularly revisited.

Our discussion mostly focused on the increasing activity of TCs in EA but we stress that there are also long-term decreasing trends in TC activity in WNP, Southeast Asia, and in the open ocean during the mature boreal autumn (Fig. $2 d-f$ ), respectively. In addition, there is also weakening trend in the East Asian subtropical jetstream (Fig. 3f, Table 1). While we can only suspect that the shift of the PDO to its negative phase has also influenced such trends in the said regions and index, we go back to our concerns on scaling where we highlighted that there are sources of variabilities unique to each region and seasons (e.g., boreal winter $)^{44}$. Therefore, the investigation of their respective trends and shifts merit future works.

Finally, our findings have shown observational evidence that the shift of the PDO to its negative phase in the mid-1990s led to the abrupt increase and significant increasing TC passage frequency, which ultimately resulted in the increasing activity of TCs in EA during the mature boreal autumn. It is expected that our findings revisit and contribute to the existing knowledge pool on understanding TC variability and predictability in the EA region and in the WNP.

\section{METHODS}

\section{Tropical cyclone best track and reanalysis dataset}

The tropical cyclone (TC) best track data are obtained from the International Best Track Archive for Climate Stewardship (IBTRACS) version 4 from 1981 to $2019^{45}$. Only named tropical cyclones with maximum sustained winds that are greater than or equal to 35 knots $\left(\sim 17 \mathrm{~ms}^{-1}\right)$ were considered in our analysis. Otherwise indicated, the timeseries is filtered using the 1-3-4-3-1 technique ${ }^{23}$. Considering the limited number of TCs in EA in November, our analysis covers the SO only. Due to the weaker TCs passing through the EA relative to the rest of the WNP, the chosen levels for environmental steering flow starts from 850 to $500 \mathrm{hPa}$. We compared the PDI and TC frequency in SO using the Regional Specialized Meteorological Center-Tokyo and the Joint Typhoon Warning Center data (Supplementary Fig. $4 \mathrm{a}-\mathrm{c}$ ) and results show that there is no considerable difference in the TC metrics from the two datasets.

The autocorrelation of TC passage frequency and PDI show significant lagged correlation at $11-14$ and $10-13$ years, respectively, while their respective periodograms confirm peak periodicity of $10-12$ years PDI (Supplementary Fig. $3 a-d$ ). Such periodicity was used as an input in the timeseries decomposition of extended TC passage frequency.

We used the Japanese Reanalysis 55-year Project from 1981 to 2019 in our observational analysis ${ }^{46}$. In the composite analysis, a positive (negative) PDO year is defined as a year that is greater than or equal (less than or equal) to the 3rd (1st) quartile range of the base period (1981 -2019 ). The negative PDO years are 2000, 2001, 2006, 2007, 2008, 2009, 2010, 2011, 2012, 2013, and 2014 while the positive PDO years 1981, 1982, 1983, 1984, 1985, 1986, 1987, 1994, 1995, and 1996.

\section{Definition of domains of analysis}

We performed supervised k-nearest neighbor clustering of TC tracks during the mature boreal autumn from 1981 to 2019 using the permutation of each TC track's first and last geographic coordinates as grouping variables. Some clusters were able to discriminate the TC tracks that passed in Southeast Asia but most clusters were not able to effectively discriminate the TC tracks between the EA and the TCs that remained in the open ocean rendering only two optimal clusters for all combination of grouping variables (Supplementary Figs. $5 \mathrm{a}-\mathrm{i}$ and $6 \mathrm{a}-\mathrm{i}$ ).

To proceed, we classified the TC tracks into three distinct geographic domains: (1) East Asia, (2) Southeast Asia, and the (3) open ocean category (Fig. 1a). All TC tracks that passed through East Asia are considered under the EA category even if they originally passed through the other domains. To create a delineated East Asian region, we used $225 \mathrm{~km}$ buffer zone away from the nearest coastline of Japan and $175 \mathrm{~km}$ away from the nearest coastline of Taiwan. Bonin Islands and the other far outlying islands of Japan were not considered as part of our delineated EA region. The boundaries of the EA region are as follows: $118^{\circ} \mathrm{E}-21^{\circ} \mathrm{N}, 118^{\circ} \mathrm{E}-48^{\circ} \mathrm{N}, 148.5^{\circ}$ $\mathrm{E}-48^{\circ} \mathrm{N}, 148.5^{\circ} \mathrm{E}-33.5^{\circ} \mathrm{N}$, and $123^{\circ} \mathrm{E}-21^{\circ} \mathrm{N}$.

Meanwhile, the TC tracks that intersected Southeast Asia belong under its namesake category. The boundaries of the Southeast Asian region are as follows: $100^{\circ} \mathrm{E}-24.5^{\circ} \mathrm{N}, 118^{\circ} \mathrm{E}-24.5^{\circ} \mathrm{N}, 118^{\circ} \mathrm{E}-21^{\circ} \mathrm{N}, 123^{\circ} \mathrm{E}-21^{\circ} \mathrm{N}, 130^{\circ} \mathrm{E}-3^{\circ} \mathrm{N}$, and $100^{\circ} \mathrm{E}-3^{\circ} \mathrm{N}$. Lastly, the TC tracks that intersected neither of the two EA and Southeast Asia are classified under the open ocean category. We explicitly clarify that these domains are not the reflection of current political boundaries.

\section{Climate indices and TC metrics}

The climate indices used in our analysis are defined as follows:

- Pacific Decadal Oscillation index-5-year smoothed leading principal component of annual SST north of $20^{\circ} \mathrm{N}$ in the Pacific Ocean ${ }^{28}$.

- Tripole index for the Interdecadal Pacific Oscillation-5-year smoothed difference in annual SST anomalies over the central and equatorial Pacific, and the northwest and southwest Pacific ${ }^{28}$.

- Indian Ocean Basin Wide SST-areal-averaged SO SST anomalies over the tropical Indian Ocean defined at $-20^{\circ} \mathrm{S}-20^{\circ} \mathrm{N}, 40-100^{\circ} \mathrm{E}^{29}$.

- Tropical North Atlantic SST-area-averaged SO SST anomalies over the tropical North Atlantic defined at $-5.5^{\circ} \mathrm{N}-23.5^{\circ} \mathrm{N}, 305-345^{\circ} E^{28}$.

- Niño 4 index-areal-averaged SO SST anomalies over the central equatorial Pacific Ocean defined at $-5^{\circ} \mathrm{S}-5^{\circ} \mathrm{N}, 160-210^{\circ} \mathrm{E}^{28}$ ]

- Atlantic Meridional Oscillation index: 5-year smoothed area-weighted annual SST from 0 to $70^{\circ} \mathrm{N}$ in the Atlantic Ocean ${ }^{28}$.

- Western North Pacific subtropical high zonal index-areal-averaged $500 \mathrm{hPa}$ relative vorticity ${ }^{25}$ defined at $20-30^{\circ} \mathrm{N}, 120-135^{\circ} \mathrm{E}$.

- East Asian subtropical jetstream index-areal-averaged $300 \mathrm{hPa}$ horizontal wind speed ${ }^{27}$ defined at $25-40^{\circ} \mathrm{N}, 110-150^{\circ} \mathrm{E}$.

- Cost of damages - deflated annual total cost of damages in East Asia associated with tropical cyclones ${ }^{1}$. We used the Consumer Price Index (CPI) from the World Bank ${ }^{2}$ to deflate the cost of damages (Supplementary Fig. 7). The deflated cost of damages is calculated by dividing the actual cost of damages by the CPI and multiplied by 100 .

- Power Dissipation Index-integral of the cubes of six-hourly maximum sustained wind that is greater than 35 knots. For scaling, we converted 
the knots to $\mathrm{ms}^{-1}$ where 1 knots $=0.514 \mathrm{~ms}^{-1}$. Refer to the previous report $^{23}$ for the detailed explanation of decomposing the PDI into its components: TC number, duration, and intensity.

\section{Statistical tests}

The Pearson's correlation is the selected measure of correlation and partial correlation in our study where their significance is tested using two-tailed distribution. The student's t-test statistic with two-tailed distribution is used to test the significance of difference in sampled mean between the two periods. We applied 1,000 simulations in the student's t-test using Monte Carlo Test to minimize the influence of uncertainty in the significance of the sampled groups. The power analysis of the sampled means using an alpha of 0.05 and effect size using Cohen's $\mathrm{d}^{47}$ was performed to test the power of significance of difference between the two periods.

Using the Rodionov algorithm ${ }^{48,49}$, we calculated the regime shift of the 1-3-4-3-1 filtered timeseries ${ }^{23}$ with a cut-off length of 10, Hubert's Parameter of 1 , and significance level at $p<0.01$ level. We applied the detected regime shifts during the Period 1 (1981-1998) and Period 2 (1999-2019) in our analysis. The standardized linear regression coefficients of PDI and its components were used to calculate how the percentage contribution of each component to the total PDI variance. The significance of trend in timeseries was tested using the Mann-Kendall Test after correcting for autocorrelation in the timeseries itself ${ }^{50}$.

\section{DATA AVAILABILITY}

The reanalysis data products used in the analysis are available for download from their respective websites.

\section{CODE AVAILABILITY}

The codes used in the analysis are available upon request.

Received: 16 April 2021; Accepted: 6 December 2021; Published online: 20 January 2022

\section{REFERENCES}

1. EM-DAT: The international disasters database. EM-DAT: The international disasters database (Accessed: 4th January 2021); https://www.emdat.be/.

2. Consumer Price Index $(2010=100)$. East Asia and the Pacific (Accessed: 8 th June 2021); https://data.worldbank.org/indicator/FP.CPI.TOTL?locations=Z4.

3. Gill, I. S. \& Kharas, H. An East Asian Renaissance: Ideas for Economic Growth (World Bank, 2007).

4. World Economic Outlook: October 2020. International Monetary Fund. (Accessed: 08 June 2021); https://www.imf.org/en/Publications/WEO/Issues/2020/09/30/ world-economic-outlook-october-2020.

5. Liu, K. \& Chan, J. Inactive Period of Western North Pacific Tropical Cyclone Activity in 1998-2011. J. Clim. 26, 2614-2630 (2013).

6. Liu, K. \& Chan, J. Interdecadal variation of frequencies of tropical cyclones, intense typhoons and their ratio over the western North Pacific. Int. J. Climatol. 40, 3954-3970 (2019).

7. Zhao, H. \& Wang, C. Interdecadal modulation on the relationship between ENSO and typhoon activity during the late season in the western North Pacific. Clim. Dyn. 47, 315-328 (2016).

8. Choi, Y., Ha, K., Ho, C. \& Chung, C. Interdecadal change in typhoon genesis condition over the western North Pacific. Clim. Dyn. 45, 3243 (2015).

9. Hong, C., Wu, Y. \& Li, T. Influence of climate regime shift on the interdecadal change in tropical cyclone activity over the Pacific Basin during the middle to late 1990s. Clim. Dyn. 47, 2587-2600 (2016).

10. Tu, S., Xu, F. \& Xu, J. Regime shift in the destructiveness of tropical cyclones over the Western North Pacific. Environ. Res. Lett 13, 094021 (2018).

11. Hsu, P., Chu, P., Murakami, H. \& Zhao, X. An abrupt decrease in the late-season typhoon activity over the western North Pacific. J. Clim. 27, 4296-4312 (2014).

12. Choi, J., Cha, Y., Kim, T. \& Kim, H. Interdecadal variation of tropical cyclone genesis frequency in late season over the Western North Pacific. Int. J. Climatol. 37, 4335-4346 (2017).

13. He, $\mathrm{H}$. et al. Unusual growth in intense typhoon occurrences over the Philippine Sea in September after the mid-2000s. Clim. Dyn. 48, 1893-1910 (2017).

14. Wang, X. \& Liu, H. PDO modulation of ENSO effect on tropical cyclone rapid intensification in the western North Pacific. Clim. Dyn. 46, 15-28 (2016).
15. Wu, Q., Wang, X. \& Tao, L. Interannual and interdecadal impact of Western North Pacific Subtropical High on tropical cyclone activity. Clim. Dyn. 54, 2237-2248 (2020).

16. Camp, J. et al. The western Pacific subtropical high and tropical cyclone landfall: Seasonal forecasts using the Met Office GloSea5 system. Q. J. R. Meteorol. Soc. 145, 105-116 (2018).

17. Jin, C. et al. Critical role of northern off-equatorial sea surface temperature forcing associated with Central Pacific El Niño in more frequent tropical cyclone movement toward East Asia. J. Clim. 26, 2534-2545 (2013).

18. Park, D., Ho, C., Kim, J. \& Kim, H. Strong landfall typhoons in Korea and Japan in a recent decade. J. Geophys. Res. 116, D07105 (2011).

19. Park, D., Ho, C. \& Kim, J. Growing threat of intense tropical cyclones to East Asia over the period 1977-2010. Environ. Res. Lett 9, 014008 (2014).

20. Wu, L., Wang, B. \& Geng, S. Growing typhoon influence on East Asia. Geophys. Res. Lett. 32, L18703 (2005).

21. Lee, M. et al. Long-term trends in tropical cyclone tracks around Korea and Japan in late summer and early fall. Atmos. Sci. Lett 20, e939 (2019).

22. Emanuel, K. Increasing destructiveness of tropical cyclones over the past 30 years. Nature 436, 686-688 (2005).

23. Emanuel, K. Environmental Factors Affecting Tropical Cyclone Power Dissipation. J. Clim. 20, 5497-5509 (2007).

24. Wang, B., Xiang, B. \& Lee, J. Subtropical High predictability establishes a promising way for monsoon and tropical storm predictions. Proc. Natl Acad. Sci. USA 110, 2718-2722 (2013).

25. Lu, R., Li, Y. \& Ryu, C. Relationship between the zonal displacement of the western Pacific subtropical high and the dominant modes of low-tropospheric circulation in summer. Prog. Nat. Sci. 18, 161-165 (2008).

26. Yang, H. \& Sun, S. The characteristics of longitudinal movement of the subtropical high in the western Pacific in the pre-rainy season in South China. Adv. Atmos. Sci. 60, 1222-1224 (2005).

27. Huang, D. et al. The different configurations of the East Asian Polar Front Jet and Subtropical Jet and the associated rainfall anomalies over Eastern China in summer. J. Clim. 27, 8205-8220 (2014).

28. Climate Indices. Monthly Atmospheric and Ocean Time-Series (2020). (Accessed: 4th January 2021); https://psl.noaa.gov/data/climateindices/list/.

29. El Niño Monitoring Indices. Tokyo Climate Center (Accessed: 4th January 2021); https://ds.data.jma.go.jp/tcc/tcc/products/elnino/index/.

30. Wang, H., Kumar, A., Wang, W. \& Xue, Y. Seasonality of the Pacific Decadal Oscillation. J. Clim. 25, 25-38 (2012).

31. Zhang, L. \& Delworth, T. Simulated response of the Pacific Decadal Oscillation to climate change. J. Clim. 29, 5999-6018 (2016).

32. Mantua, N. \& Hare, S. The Pacific Decadal Oscillation. J. Oceanogr. 58, 35-44 (2002).

33. Yang, S., Lau, K. M. \& Kim, K. M. Variations of the East Asian jet stream and Asian-Pacific-American winter climate anomalies. J. Clim. 153, 306-325 (2002).

34. Park, G. Correlation between the Pacific Decadal Oscillation and East/Japan Sea SST in the autumn. J. Korean Soc. Oceanogr. 24, 509-518 (2019).

35. Park, J. H. \& An, S. I. The impact of tropical western Pacific convection on the North Pacific atmospheric circulation during the boreal winter. Clim. Dyn. 43, 2227-2238 (2014).

36. Kim, M. H., \& Moon, I. J. Evaluation of the reliability of tropical cyclone data using ENSO. Asia Pac. J. Atmos. Sci. https://doi.org/10.1007/s13143-021-00260-3 (2021).

37. Moon, I. J., Kim, S. H. \& Chan, J. Climate change and tropical cyclone trend. Nature 570, E3-E5 (2019).

38. Chen, S. et al. The dominant North Pacific atmospheric circulation patterns and their relations to Pacific SSTs: historical simulations and future projections in the IPCC AR6 models. Clim. Dyn. 56, 701-725 (2020).

39. Flato, G. et al. In Climate Change 2013: The Physical Science Basis. Contribution of Working Group I to the Fifth Assessment Report of the Intergovernmental Panel on Climate Change (eds. Stocker, T. F et al.) 741-882 (Cambridge University Press, 2013).

40. Eyring, V. et al. ESMValTool (v1.0)-a community diagnostic and performance metrics tool for routine evaluation of Earth system models in CMIP. Geosci. Model Dev. 9, 1747-1802 (2016).

41. Mann, M., Steinman, B. \& Miller, S. Absence of internal multidecadal and interdecadal oscillations in climate model simulations. Nat. Commun. 11, 49 (2020).

42. Mann, M., Steinman, B. \& Miller, S. Multidecadal climate oscillations during the past millennium driven by volcanic forcing. Science 371, 6533 (2021).

43. Beaufort, L. \& Grelaud, M. A 2700-year record of ENSO and PDO variability from the Californian margin based on coccolithophore assemblages and calcification. Prog. Earth. Planet. Sci. 4, 5 (2017).

44. Basconcillo, J. \& Moon, I. J. Recent increase in the occurrences of Christmas typhoons in the Western North Pacific. Sci. Rep. 11, 7416 (2021).

45. Knapp, K., Kruk, M., Levinson, D., Diamond, H. \& Neumann, C. The International Best Track Archive for Climate Stewardship (IBTrACS). Bull. Am. Meteorol. Soc. 91, 363-376 (2010). 
46. Kobayashi, S. et al. The JRA-55 reanalysis: General specifications and basic characteristics. J. Meteorol. Soc. Jpn. 93, 5-48 (2015).

47. Cohen, J. Statistical Power Analysis for the Behavioral Sciences (L. Erlbaum Associates, 1988).

48. Rodionov, S. A sequential algorithm for testing climate regime shifts. Geophys. Res. Lett. 31, 9 (2004).

49. Rodionov, S. The use of prewhitening in climate regime shift detection. Geophys. Res. Lett. 31, 12 (2006).

50. Hamed, K. \& Rao, A. A modified Mann-Kendall trend test for autocorrelated data. J. Hydrol. 204, 182-196 (1998).

\section{ACKNOWLEDGEMENTS}

This research is supported by the Basic Science Research Program, through the National Research Foundation of Korea (NRF) funded by the Ministry of Education (2021R1A2C1005287) and a part of the project titled 'Improvements of ocean prediction accuracy using numerical modeling and artificial intelligence technology' and "Establishment of the ocean research station in the jurisdiction zone and convergence research", funded by the Ministry of Oceans and Fisheries in Korea. The authors would also like to acknowledge the following: the Interactive Assessment of the Climate Systems-Tokyo Climate Center, the Physical Sciences LaboratoryNational Oceanic and Atmospheric Administration, the Philippine Atmospheric, Geophysical, and Astronomical Services Administration, Dr. Reniel Pamplona, Ms. Cherin Kim, and Mr. Chris John Delantes.

\section{AUTHOR CONTRIBUTIONS}

J.Q.B. and I.J.M. designed and conducted the study, and wrote the manuscript.

\section{COMPETING INTERESTS}

The authors declare no competing interests.

\section{ADDITIONAL INFORMATION}

Supplementary information The online version contains supplementary material available at https://doi.org/10.1038/s41612-021-00222-6.

Correspondence and requests for materials should be addressed to II-Ju Moon

Reprints and permission information is available at http://www.nature.com/ reprints

Publisher's note Springer Nature remains neutral with regard to jurisdictional claims in published maps and institutional affiliations.

Open Access This article is licensed under a Creative Commons Attribution 4.0 International License, which permits use, sharing, adaptation, distribution and reproduction in any medium or format, as long as you give appropriate credit to the original author(s) and the source, provide a link to the Creative Commons license, and indicate if changes were made. The images or other third party material in this article are included in the article's Creative Commons license, unless indicated otherwise in a credit line to the material. If material is not included in the article's Creative Commons license and your intended use is not permitted by statutory regulation or exceeds the permitted use, you will need to obtain permission directly from the copyright holder. To view a copy of this license, visit http://creativecommons. org/licenses/by/4.0/.

(c) The Author(s) 2022 